\title{
Work correlates of back problems and activity restriction due to musculoskeletal disorders in the Canadian national population health survey (NPHS) 1994-5 data
}

\author{
D C Cole, S A Ibrahim, H S Shannon, F Scott, J Eyles
}

\begin{abstract}
Objectives-To describe the prevalence of musculoskeletal problems in the Canadian working population and to determine cross sectional associations between such problems and work factors, particularly job strain and physical demand variables. Methods-The Canadian 1994 national population health survey (NPHS) sampled 4230 working men and 4043 working women (ages 18-64) who answered an abbreviated version of the job content questionnaire. Workers were classified into four strain categories: high, passive, active, and low. Outcomes were restricted activity due to musculoskeletal disorders and the diagnosis of a back problem (both yes or no). Survey weights were incorporated to allow for different probabilities of selection. Logistic regression analyses were carried out separately for women and men, controlling for sociodemographic factors.
\end{abstract}

Results-Prevalence of chronic back problems diagnosed by a health practitioner was $14.5 \%$ among men and $12.5 \%$ among women. Men had a $6.6 \%$ prevalence of restricted activity due to musculoskeletal disorders, whereas the corresponding figure for women was $5.3 \%$. Women, but not men, in high strain jobs were more likely to report both back problems (odds ratio (OR) $1.60,95 \%$ confidence interval (95\% CI) 1.14 to 2.28 ) and restricted activity (OR $1.98,95 \%$ CI 1.16 to 3.48) compared with those in low strain jobs. High physical exertion was an independent predictor of back problems in both sexes. For both men and women, low social support at work and high job insecurity were independent predictors of restricted activity due to musculoskeletal disorders. Conversely, chronic back problems contributed to explanation of high job strain among women (OR $1.76,95 \%$ CI 1.30 to 2.39 ) and high physical exertion among men (OR 1.39, 95\% CI 1.09 to 1.77), whereas restricted activity due to musculoskeletal disorders contributed to explanation of high job insecurity in both sexes.

Conclusions-Associations of interest between work stressors and musculoskeletal problems in this cross sectional study provide evidence for physical and psychosocial factors both affecting disability and being affected by disability in a working population.

(Occup Environ Med 2001;58:728-734)

Keywords: back pain; cross sectional survey; job strain; Canada

Population based surveys have documented the important role of musculoskeletal disorders as sources of disability. For $20 \%$ of people aged 30 years or more, musculoskeletal disorders were their main source of disability in the mini-Finland health survey. ${ }^{1}$ The national 1986-7 Canadian health and activity limitation survey (HALS) gave estimates of 1:20 Canadian adults with physical disabilities attributable to musculoskeletal disorders. ${ }^{2}$ In the United States national health interview survey (NIHS) data back pain often caused activity limitation among people under 45 years of age. ${ }^{3}$

Population based surveys have also shown associations between work factors and musculoskeletal disorders. Some have focused on physical factors - for example, sitting, driving, lifting, awkward postures, and vibration in an Ontario provincial survey. ${ }^{4}$ Others have included psychosocial items at work, such as job dissatisfaction in a Belgian national survey. ${ }^{5}$ More comprehensive surveys have included both physical and psychosocial work factorsfor example, associations between back pain and each of physically heavy, monotonous, and repetitive work among Swedish adults. ${ }^{6}$ Survey analyses that compared joint prevalence of exposure and controlled for different types of work factors - for example, The Netherlands national work and living conditions survey ${ }^{7}-$ are less common.

Despite the ambiguous temporal relations inherent in cross sectional data, most surveys have been interpreted as contributing to evidence for an aetiological role of physical and psychosocial work factors in the development of musculoskeletal disorders. ${ }^{89}$ Less commonly have results been cast as comparisons between the experience of physical and psychosocial work factors by those with chronic musculoskeletal disorders and those without. ${ }^{6}$ This perspective becomes increasingly important as modified work and equal opportunity strategies promote integration for those with disabilities into the workplace. ${ }^{10}$

The 1994-5 Canadian national population health survey (NPHS) included questions on 
activity limitation due to chronic conditions, chronic back problems, and work factors, with questions based on Karasek's job content questionnaire among large enough numbers of working women and men to permit sex stratified analyses, taking into account relevant sociodemographic and behavioural factors. In this paper, we first report the prevalence of two self reported measures of musculoskeletal disorders: back problems diagnosed by a health professional and restricted activity due to musculoskeletal disorders, both separately and together. We note how they vary by sociodemographic, health behaviour, and work factors and set out correlations among psychosocial and physical work factors. Finally, we examine associations between work factors and each of the musculoskeletal disorders that control for other factors. We interpret these associations from both an aetiological view (work factors as independent variables and musculoskeletal disorders as dependent variables) and a disability view (musculoskeletal disorders as independent variables and work factors as dependent variables) to prompt consideration of the relevance of both interpretations.

\section{Methods}

POPULATION

The 1994-5 Canadian NPHS was a nationwide household survey in all provinces and territories. Samples were included from all household residents, excluding only people living on Indian reserves, on Canadian forces bases, and in some remote areas. Sampling was conducted according to a multistage complex design. In the first stage, homogenous strata were formed and independent samples of clusters were drawn from each stratum. In the second stage, household lists were prepared for each cluster and households were selected from the lists. Within each selected household, all residents were administered a structured questionnaire, with one respondent aged 12 years or older selected at random for a more detailed interview. The response rate for households was $88.7 \%$ and for selected panel respondents $96.1 \%$. Responses were weighted to be representative of the sample population and to adjust for response rates.

Our analyses used the NPHS public use data file of the respondents to the detailed interviews aged 18-64 who were currently working. ${ }^{11}$ Among them, 4230 men and 4043 women from a wide range of occupations ${ }^{12}$ answered a modified and abbreviated version of the job content questionnaire. ${ }^{13}$ Detailed information about the NPHS ${ }^{11} 14$ and descriptions of the working population ${ }^{15}$ can be found elsewhere.

\section{MEASURES}

\section{Musculoskeletal disorders}

Among the NPHS self reported health measures were a question on chronic conditions and a separate set of questions on activity restrictions (see appendix). In the first question, the interviewer asked about long term conditions (having lasted or being expected to last 6 months or more) that had been diagnosed by a health professional. One of the responses on the list was "back problems excluding arthritis" which we henceforth refer to simply as "back problems". The set of questions on activity restrictions tapped both long term physical or mental conditions or health problems that limited the type or amount of activity the respondent could do in various spheres of life, and long term disabilities or handicaps. A derived variable, restriction of activity, was constructed by Statistics Canada staff to capture yes responses to any of these questions. Supplementary open ended questions on the main condition or health problem causing the activity restriction or long term disability or handicaps respectively, were first coded with the ninth revision of the international classification of diseases (ICD-9) codes and then recoded into groups (see appendix). We grouped musculoskeletal conditions, into "restricted activity due to musculoskeletal disorders" and a range of "other conditions". Unfortunately the spheres of life-for example, work-where respondents experienced the activity restrictions were not separately flagged.

\section{Work variables}

Job type was classified with the Pineo dichotomous job category blue collar (including forepersons, skilled crafts and trades, farmers and farm labourers, and semiskilled and unskilled manual) and white collar (professionals, high level management, semiprofessionals, technicians, middle management, supervisors, and clerical-sales-service) ${ }^{16}$ Additional categorisation was by part time ( $<30$ hours) versus full time and shift for main job (regular without weekend, regular with weekend, irregular with and without weekend).

Work stress variables used a five point Likert scale format (by contrast with the four point scale in the original job content questionnaire) with responses ranging from "strongly agree" to "strongly disagree." Psychological demands were measured with a two item scale (hectic work and conflicting demands). Decision latitude or "control" was measured with a five item scale (learn new things, job requires high level of skill, freedom to decide how to do the job, work not repetitious, a lot of say about what happens in the job). Social support at work was measured with a three item scale (supervisor helpful in getting work done, coworkers helpful in getting work done, people you work with not hostile). Psychological demands, decision latitude, and social support at work were dichotomised as high or low making the cut off point as close as possible to the median of their respective distributions (only in the case of social support did this consistently include more than $50 \%$ of the subjects below the cut off point). We formulated Karasek's job strain construct in two generally accepted ways, ${ }^{17}$ firstly, by including decision latitude, psychological demands, and an interaction term; and secondly by classifying jobs as high strain (low decision latitude and high psychological demands), active (high decision latitude and high psychological demands), passive (low 
decision latitude and low psychological demands) or low strain (high decision latitude and low psychological demands). However, as the interaction term was non-significant in modelling and the gradients of high to low strain inconsistent, we present results for the two scales, decision latitude and psychological demands, as independent factors.

Job insecurity and physical exertion were each measured with single items and dichotomised into high and low categories. High insecurity or exertion was defined as agreeing or strongly agreeing that their job was insecure (high exertion meant that they agreed or strongly agreed that their physical exertion at work was high).

Social, demographic, and health behaviour variables

We controlled for the following available variables, found to be correlates of back problems and musculoskeletal restrictions both in the literature $e^{481819}$ and in our univariate analyses (variable and categories): age (18-34, 35-44, 45-54, 55-64); level of education (less than secondary, secondary, some college or university, college or university complete); household income from Statistics Canada definitions (low, lower middle, middle, and upper); marital status (never married, married or common law, widowed or separated); smoking (non-smoker, current smoker, former smoker); and leisure time physical activity (regular, irregular, or occasional).

ANALYSIS

Among those who were working, a nonresponse analysis was conducted, which compared measures of musculoskeletal disorders, social and health behaviour data, and available work variables among those answering and those not answering the questions in the job content questionnaire. Differences were assessed with $\chi^{2}$ tests. Overlap in musculoskeletal disorder measures among respondents was compared with a simple two by three frequency table. Frequency tables were constructed with listwise deletion - that is, only respondents to all questions were included. $\chi^{2}$ Tests were conducted to assess bivariate associations between musculoskeletal disorders and social and health behaviour data, and work factors, with a significance level of 0.05 . Pearson correlations were calculated across the different work variables of the job content questionnaire .

Before modelling, a non-response analysis was performed on those answering the job content questionnaire for the only two variables with a non-response rate $>1 \%$ : income (rate of $4.7 \%$ for men and $3.5 \%$ for women) and job type $(3.6 \%$ for men and $3.1 \%$ for women). Respondents and non-respondents for these two variables were compared by the measures of musculoskeletal disorder and psychosocial variables at work with the differences assessed by $\chi^{2}$ tests. Those not reporting their income were not significantly different from respondents for all relevant variables and were therefore excluded across all models. None of those who did not report their job type reported musculoskeletal problems, creating a complete separation between respondents and non-respondents for this variable. Hence, nonrespondents to job type also had to be excluded from all models.

For modelling purposes, work, social, and behavioural variables were treated as independent variables, and musculoskeletal disorders as binary dependent variables. We ran separate models with each of the formulations of job strain already noted. Because the interactions between demands and control were not significant and the contributions of each factor were more obvious when presented separately, we included only the main effects. Social and behavioural independent variables were removed from the multivariable logistic models one variable at a time, provided that the variable was not significant $(p>0.05)$ and that such omission did not alter significantly $(10 \%$ chang $^{20}$ ) the estimated odds ratios (ORs) of other variables in the model.

Separate analyses were carried out for men and women. Adjusted survey weights that add to the sample size were used in estimating prevalences. As the NPHS used a complex sample design involving both clustering and stratification, we used a weighted analysis which considered data structure. ${ }^{21}{ }^{22}$ Statistics Canada recommends use of standard survey weights and provides bootstrap weights to estimate the regression models for NPHS data. ${ }^{11}$ Using these bootstrap weights is equivalent to using software such as SUDAAN that can estimate complex sample variances. The HosmerLemeshow $^{23}$ and deviance $\chi^{2}$ goodness of fit statistics were used to assess the fit of the final logistic regression models. All statistical analyses were performed with the SAS version $6.12^{24}$ software package.

\section{Results}

Among working men $14.1 \%$ did not answer the job content questionnaire, whereas $8.4 \%$ of women did not. Responders and nonresponders had comparable age and income distributions and prevalences of musculoskeletal disorders. Women respondents were less likely to be working part time $(71.5 \% v$ $78.6 \%$ of non-respondents, $p=0.02)$. Men respondents were less likely to be blue collar $(48.7 \%$ v $54.7 \%, \mathrm{p}=0.006)$, college or university graduates $(38.5 \%$ v $45.5 \%, \mathrm{p}=0.003)$, married or common law $(70.5 \%$ v $78.0 \%$, $\mathrm{p}=0.0008)$, or current smokers $(33.3 \% v$ $40.9 \%, \mathrm{p}=0.004)$.

Among respondents to job content questionnaire questions, overall prevalence of self reported chronic back problems diagnosed by a health professional was $14.5 \%$ for men and $12.5 \%$ for women. Men had a $6.6 \%$ prevalence of restricted activity due to musculoskeletal disorders, whereas the corresponding figure for women was $5.3 \%$. Some overlap between back problems and restricted activity due to musculoskeletal disorders occurred-for example, $55.7 \%$ of men with restricted activity due to musculoskeletal disorders reported back problems (table 1). Interestingly, musculoskeletal disorders surpassed all other disorders 
Table 1 Cross classification of presence of back problems and restriction of activity, by sex

\begin{tabular}{llll}
\hline \multicolumn{4}{c}{ Activity restriction } \\
\cline { 2 - 4 } Back problems & $\begin{array}{l}\text { Musculoskeletal } \\
n(\text { row\%, column\%) }\end{array}$ & $\begin{array}{l}\text { Other main cause } \\
n(\text { row\%, column\%) }\end{array}$ & $\begin{array}{l}\text { No restriction } \\
n(\text { row\%, column\%) }\end{array}$ \\
\hline $\begin{array}{l}\text { Men: } \\
\text { Yes }\end{array}$ & $158(26,56)$ & $49(8,18)$ & $398(66,11)$ \\
No & $126(4,44)$ & $224(6,82)$ & $3248(90,89)$ \\
Total & $284(7,100)$ & $273(6,100)$ & $3647(87,100)$ \\
$\begin{array}{l}\text { Women: } \\
\text { Yes }\end{array}$ & $114(23,53)$ & $78(16,24)$ & $305(61,9)$ \\
No & $100(3,47)$ & $243(7,76)$ & $3173(90,91)$ \\
Total & $214(5,100)$ & $321(8,100)$ & $3478(87,100)$ \\
\hline
\end{tabular}

Table 2 Prevalence of back problems and restriction of musculoskeletal activity for each category of sociodemographic and health behaviour variables, by sex*

\begin{tabular}{|c|c|c|c|c|}
\hline \multirow[b]{2}{*}{ Variable } & \multicolumn{2}{|c|}{ Back problems (\% yes) } & \multicolumn{2}{|c|}{$\begin{array}{l}\text { Musculoskeletal activity } \\
\text { restriction (\% yes) }\end{array}$} \\
\hline & $\begin{array}{l}\text { Men } \\
(n=4209)\end{array}$ & $\begin{array}{l}\text { Women } \\
(n=4027)\end{array}$ & $\begin{array}{l}\text { Men } \\
(n=3899)\end{array}$ & $\begin{array}{l}\text { Women } \\
(n=3679)\end{array}$ \\
\hline \multicolumn{5}{|l|}{ Age: } \\
\hline $18-34$ & 11.5 & 10.7 & 5.9 & 4.4 \\
\hline $35-44$ & 13.9 & 12.7 & 8.4 & 5.9 \\
\hline $45-54$ & 18.7 & 14.1 & 7.7 & 7.0 \\
\hline $55-64$ & 20.0 & 17.7 & 8.4 & 10.1 \\
\hline \multicolumn{5}{|l|}{ Household income: } \\
\hline Lower/lower middle income & 14.4 & 12.3 & 12.3 & 5.5 \\
\hline Middle income & 13.4 & 11.8 & 7.7 & 6.3 \\
\hline Upper middle income & 14.7 & 12.8 & 5.7 & 6.0 \\
\hline Higher income & 14.4 & 13.3 & 7.6 & 5.3 \\
\hline Missing & 18.9 & 10.4 & 7.2 & 3.2 \\
\hline \multicolumn{5}{|l|}{ Education: } \\
\hline Less than secondary & 15.5 & 13.6 & 7.8 & 8.2 \\
\hline Secondary complete & 11.8 & 11.7 & 6.8 & 4.1 \\
\hline Some college university & 17.1 & 12.9 & 8.0 & 6.6 \\
\hline College/university complete & 13.4 & 12.2 & 6.6 & 5.2 \\
\hline \multicolumn{5}{|l|}{ Marital status: } \\
\hline Never married & 8.8 & 10.9 & 5.0 & 5.0 \\
\hline Married/common law & 16.2 & 12.6 & 7.8 & 5.3 \\
\hline Widowed/separated/divorced & 16.8 & 15.1 & 9.2 & 10.7 \\
\hline \multicolumn{5}{|l|}{ Smoking: } \\
\hline Current smoker & 16.0 & 14.8 & 9.5 & 7.2 \\
\hline Former smoker & 16.5 & 12.6 & 7.0 & 6.4 \\
\hline Non-smoker & 11.2 & 10.8 & 5.3 & 4.3 \\
\hline \multicolumn{5}{|l|}{ Leisure time physical activity: } \\
\hline Regular & 14.3 & 11.4 & 7.8 & 6.0 \\
\hline Occasional/irregular & 14.8 & 13.8 & 6.6 & 5.5 \\
\hline
\end{tabular}

${ }^{\star}$ Listwise deletion for all variables except income, where missing category was created.

Table 3 Prevalence of back problems across levels of work variables by sex*

\begin{tabular}{|c|c|c|c|c|}
\hline \multirow[b]{2}{*}{ Variable } & \multicolumn{2}{|c|}{$\operatorname{Men}(n=4209)$} & \multicolumn{2}{|c|}{ Women $(n=4027)$} \\
\hline & $n$ & $\%$ yes & $n$ & $\%$ yes \\
\hline \multicolumn{5}{|l|}{ Decision latitude (control): } \\
\hline Low & 2214 & 13.4 & 2088 & 12.7 \\
\hline High & 1995 & 15.7 & 1939 & 12.3 \\
\hline \multicolumn{5}{|l|}{ Psychological demands (demand): } \\
\hline High & 2043 & 15.8 & 2057 & 15.1 \\
\hline Low & 2166 & 13.3 & 1970 & 9.8 \\
\hline \multicolumn{5}{|l|}{ Work social support: } \\
\hline Low & 2262 & 15.7 & 2179 & 13.4 \\
\hline High & 1947 & 13.1 & 1848 & 11.5 \\
\hline \multicolumn{5}{|l|}{ Job insecurity: } \\
\hline High & 857 & 14.8 & 848 & 14.9 \\
\hline Low & 3352 & 14.4 & 3179 & 11.9 \\
\hline \multicolumn{5}{|l|}{ Work physical exertion: } \\
\hline High & 2106 & 16.0 & 1629 & 15.0 \\
\hline Low & 2103 & 13.0 & 2398 & 10.9 \\
\hline \multicolumn{5}{|l|}{ Work: } \\
\hline Full time & 3840 & 14.8 & 2884 & 12.6 \\
\hline Part time & 369 & 11.2 & 1143 & 12.3 \\
\hline \multicolumn{5}{|l|}{ Shift for main job: } \\
\hline Irregular (with/without weekend) & 991 & 15.7 & 860 & 13.5 \\
\hline Regular (with weekend) & 1036 & 15.1 & 775 & 13.9 \\
\hline Regular (no weekend) & 2182 & 13.6 & 2392 & 11.7 \\
\hline \multicolumn{5}{|l|}{ Job type: } \\
\hline Blue collar & 2040 & 15.5 & 578 & 11.8 \\
\hline White collar & 2019 & 13.7 & 3326 & 12.8 \\
\hline Missing & 150 & 12.3 & 123 & 9.3 \\
\hline
\end{tabular}

${ }^{\star}$ Listwise deletion for all variables except job category, where missing category was created. combined as the main cause of activity restriction among working men $(51 \%$ of those with activity restrictions) and they were an important cause among women $(40 \%$ of those with activity restrictions).

Table 2 shows prevalences of musculoskeletal disorder by categories of sociodemographic and behavioural variables. Prevalence of a back problem increased with age for both sexes (Mantel-Haenszel $\chi^{2}\left(\mathrm{MH} \chi^{2}\right), \mathrm{p}$ values: men 20.1, $\mathrm{p}<0.0001$; women 8.6, $\mathrm{p}=0.003)$, as did restricted activity due to musculoskeletal disorders for women $\left(\mathrm{MH} \chi^{2}\right.$ $9.8, \mathrm{p}=0.002)$. Single respondents tended to have the lowest prevalence of back problems (men $\mathrm{MH} \chi^{2}$ 8.1, $\mathrm{p}=0.004$ ) and restricted activity due to musculoskeletal disorders (women $\mathrm{MH} \chi^{2}$ 7.1, $\mathrm{p}=0.008$ ). Non-smokers also had the lowest prevalences of back problems (men $\mathrm{MH} \chi^{2}$ 8.1, $\mathrm{p}=0.004$; women $\left.\mathrm{MH} \chi^{2} 6.4, \mathrm{p}=0.01\right)$ and restricted activity due to musculoskeletal disorders (men $\mathrm{MH} \chi^{2} 10.7$, $\mathrm{p}=0.001$; women $\mathrm{MH} \chi^{2}$ 6.4, $\mathrm{p}=0.01$ ).

In univariate associations with work variables, higher psychological demands were associated with significantly higher prevalence of both musculoskeletal disorders among women (back problems $\chi^{2} 15.6, p<0.0001$; restricted activity due to musculoskeletal disorders $\chi^{2} 10.7, \mathrm{p}=0.001$, tables 3 and 4 ). Lower work social support was associated with higher prevalences of restricted activity due to musculoskeletal disorders (men $\chi^{2} 4.2, \mathrm{p}=0.04$; women $\left.\chi^{2} 8.8, \mathrm{p}=0.003\right)$, as was higher job insecurity (men $\chi^{2} 7.4, \mathrm{p}=0.006$; women $\chi^{2} 6.0$, $\mathrm{p}=0.009)$. Higher physical exertion on the job was associated with higher prevalences of back problems for both sexes (men $\chi^{2} 4.5, \mathrm{p}=0.03$; women $\left.\chi^{2} 9.1, \mathrm{p}=0.003\right)$. Interestingly, decision latitude showed inconsistent relations with musculoskeletal disorders.

Among the work variables, all correlations (table 5) were relatively weak for both sexes (none >-0.22). Interestingly, psychological demands and social support at work were inversely related, as were decision latitude and physical exertion.

Table 6 shows the adjusted ORs and 95\% confidence intervals (95\% CIs) for associations between work factors and each of the musculoskeletal disorders. Although the tendency for high demand jobs to be associated with musculoskeletal disorders was present for both sexes (all ORs $>1$ ), the associations were only significant for women (OR 1.63, 95\% CI 1.26 to 2.10 for back problems and OR $1.81,95 \%$ CI 1.28 to 2.58 for restricted activity due to musculoskeletal disorders). Low social support at work was generally positively associated with musculoskeletal disorders but the association was significant only for activity restriction among women (OR 1.60, 95\% CI 1.12 to 2.30). For both sexes, high job insecurity tended to be associated with musculoskeletal disorders but the associations were significant only for activity restriction (men OR 1.50, 95\% CI 1.03 to 2.19 ; women OR $1.58,95 \%$ CI 1.08 to 2.30). Similarly, high physical exertion was associated with musculoskeletal disorders but the associations were significant only for back 
Table 4 Prevalence of restriction of activity due to musculoskeletal disorders across levels of work variables by sex*

\begin{tabular}{|c|c|c|c|c|}
\hline \multirow[b]{2}{*}{ Variable } & \multicolumn{2}{|c|}{$\operatorname{Men}(n=3899)$} & \multicolumn{2}{|c|}{ Women $(n=3679)$} \\
\hline & $n$ & $\%$ yes & $n$ & $\%$ yes \\
\hline \multicolumn{5}{|l|}{ Decision latitude (control): } \\
\hline Low & 2044 & 6.9 & 1927 & 6.0 \\
\hline High & 1855 & 7.6 & 1752 & 5.5 \\
\hline \multicolumn{5}{|l|}{ Psychological demands (demand): } \\
\hline High & 1869 & 8.0 & 1850 & 7.4 \\
\hline Low & 2030 & 6.5 & 1829 & 4.2 \\
\hline \multicolumn{5}{|l|}{ Work social support: } \\
\hline Low & 2101 & 8.2 & 1975 & 7.1 \\
\hline High & 1798 & 6.1 & 1704 & 4.2 \\
\hline \multicolumn{5}{|l|}{ Job insecurity: } \\
\hline High & 783 & 10.1 & 747 & 8.3 \\
\hline Low & 3116 & 6.5 & 2932 & 5.1 \\
\hline \multicolumn{5}{|l|}{ Work physical exertion: } \\
\hline High & 1952 & 8.2 & 1487 & 6.8 \\
\hline Low & 1947 & 6.3 & 2192 & 5.1 \\
\hline \multicolumn{5}{|l|}{ Work: } \\
\hline Full time & 3572 & 7.2 & 2636 & 5.5 \\
\hline Part time & 327 & 7.9 & 1043 & 6.4 \\
\hline \multicolumn{5}{|l|}{ Shift for main job: } \\
\hline Irregular (with/without weekend) & 929 & 8.6 & 774 & 6.9 \\
\hline Regular (with weekend) & 950 & 6.7 & 716 & 4.7 \\
\hline Regular (no weekend) & 2020 & 6.9 & 2189 & 5.7 \\
\hline \multicolumn{5}{|l|}{ Job type: } \\
\hline Blue collar & 1890 & 7.9 & 533 & 6.0 \\
\hline White collar & 1895 & 7.0 & 3048 & 5.9 \\
\hline Missing & 114 & 0.0 & 98 & 0.0 \\
\hline
\end{tabular}

^Listwise deletion of all variables except job category, where missing category was created.

Table 5 Zero order correlations between work factors (in continuous form) *

\begin{tabular}{lcrrrr}
\hline Variables & $v 1$ & $v 2$ & $v 3$ & \multicolumn{1}{c}{$v 4$} & \multicolumn{1}{c}{$v 5$} \\
\hline v1 = Decision latitude (control) & - & 0.08 & 0.11 & -0.17 & -0.15 \\
v2 = Psychological demands (demand) & 0.14 & - & -0.21 & 0.08 & 0.14 \\
v3 = Work social support & 0.07 & -0.22 & - & -0.14 & -0.07 \\
v4 = Job insecurity & -0.18 & 0.09 & -0.21 & - & 0.02 \\
v5 = Physical exertion & -0.17 & -0.05 & 0.03 & -0.02 & \multicolumn{1}{c}{-} \\
\hline
\end{tabular}

*Values below the diagonal are for men and above the diagonal, for women. $n=4230$ for men; $n=4043$ for women. musculoskeletal problems emphasise the importance of musculoskeletal conditions as sources of musculoskeletal disability among the Canadian working population. Prevalences documented here are difficult to compare with those obtained in other surveys, due to differences in wording of questions and differences in populations included. For example, the mini-Finland survey found prevalence ranging from $4.9 \%$ to $15.4 \%$ among men of working age for "continuous" low back pain, depending on the definition used. ${ }^{25}$ The Ontario health survey noted increasing prevalence of "serious trouble with back pain" or activity restrictions due to a back problem with age, from $3.2 \%$ among those aged $16-24$ to a maximum of $12.5 \%$ among those of $45-55 .{ }^{4}$ The cooccurrence of chronic back problems and restricted activity due to musculoskeletal disorders found in the NPHS, highlights the contribution of chronic back problems to population disability. ${ }^{25}$

The association between high demands and musculoskeletal disorders among women is consistent with the role of excessive psychological demands in bringing on chronic restricted activity due to musculoskeletal disorderss either as contributing factors to the onset of musculoskeletal problems (aetiological view) or as a measure of greater difficulty coping with such demands (disability view). ${ }^{26}$ Associations between low social support at work and musculoskeletal restrictions in both sexes are consistent with results of other surveys. ${ }^{72}$ Low social support may either lead to musculoskeletal disorders (aetiological view $)^{28}$ or increase handicap through lack of social supports to those with chronic musculoskeletal restrictions, consistent with a disability view.

The associations between job insecurity and restricted activity due to musculoskeletal disorders may be understood either as personal projections, based on a fluctuating capacity to regularly perform job duties, or as realistic
Discussion
Our findings that about one in eight working Canadians reported a chronic back problem diagnosed by a health professional and that almost one half of the activity restrictions among working Canadians were attributed to

Table 6 Association of work factors with musculoskeletal disorders, by sex* (estimated adjusted odds ratios (OR) (95\% CIs))

\begin{tabular}{|c|c|c|c|c|}
\hline \multirow[b]{2}{*}{ Work factors } & \multicolumn{2}{|l|}{ Men } & \multicolumn{2}{|l|}{ Women } \\
\hline & $\begin{array}{l}\text { Back problems } t \\
(n=4220) \\
\text { OR }(95 \% \text { CI })\end{array}$ & $\begin{array}{l}\text { Musculoskeletal activity } \\
\text { restrictions }(n=3772) \\
\text { OR }(95 \% \text { CI) }\end{array}$ & $\begin{array}{l}\text { Back problems } \neq \\
(n=4040) \\
\text { OR }(95 \% C I)\end{array}$ & $\begin{array}{l}\text { Musculoskeletal activity } \\
\text { restriction }(n=3691) \\
\text { OR }(95 \% \text { CI })\end{array}$ \\
\hline \multicolumn{5}{|c|}{ Decision latitude (control): } \\
\hline Low & $0.87(0.69$ to 1.11$)$ & $0.81(0.56$ to 1.17$)$ & $1.00(0.77$ to 1.29$)$ & $1.03(0.73$ to 1.44$)$ \\
\hline High $\star \star^{\star}$ & $1.00(-)$ & $1.00(-)$ & $1.00(-)$ & $1.00(-)$ \\
\hline \multicolumn{5}{|c|}{ Psychological demands (demand): } \\
\hline High & $1.21(0.96$ to 1.53$)$ & $1.19(0.85$ to 1.67$)$ & $1.63(1.26$ to 2.10$)$ & $1.81(1.28$ to 2.58$)$ \\
\hline Low $^{\star \star}$ & $1.00(-)$ & $1.00(-)$ & $1.00(-)$ & $1.00(-)$ \\
\hline \multicolumn{5}{|c|}{ Work social support: } \\
\hline Low & $1.21(0.96$ to 1.51$)$ & $1.35(0.96$ to 1.89$)$ & $1.08(0.85$ to 1.38$)$ & $1.60(1.12$ to 2.30$)$ \\
\hline $\mathrm{High}^{\star \star}$ & $1.00(-)$ & $1.00(-)$ & $1.00(-)$ & $1.00(-)$ \\
\hline \multicolumn{5}{|c|}{ Job insecurity: } \\
\hline High & $1.07(0.79$ to 1.44$)$ & $1.50(1.03$ to 2.19$)$ & $1.25(0.94$ to 1.67$)$ & $1.58(1.08$ to 2.30$)$ \\
\hline Low $^{\star \star}$ & $1.00(-)$ & $1.00(-)$ & $1.00(-)$ & $1.00(-)$ \\
\hline \multicolumn{5}{|c|}{ Physical exertion: } \\
\hline High & $1.37(1.10$ to 1.72$)$ & $1.28(0.87$ to 1.87$)$ & $1.34(1.03$ to 1.76$)$ & $1.26(0.87$ to 1.81$)$ \\
\hline 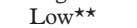 & $1.00(-)$ & $1.00(-)$ & $1.00(-)$ & $1.00(-)$ \\
\hline
\end{tabular}

^Listwise deletion was used. Variances were estimated with methods that take into account the complexity of the sampling design. †Controlled for age, education, marital status, and the significant variables in the column.

§Controlled for age, income, smoking, and the significant variables in the column.

$\ddagger$ Controlled for age, smoking, and the significant variables in the column.

TControlled for age and the significant variables in the column.

$\star \star$ Indicates reference category. $95 \%$ CI do not apply, hence $(-)$. 
assessments of persistent discrimination towards those with musculoskeletal disabilities. Certainly the qualitative literature indicates issues around legitimacy of ongoing back pain ${ }^{29}$ among workers. Prolonged work disability is also common among those with back pain and musculoskeletal conditions, ${ }^{30}{ }^{31}$ giving grounds for fears of job insecurity. The extent to which job loss or job changes may occur was assessed through the occupational supplement to the United States national health interview survey for those with back pain during the past year. ${ }^{32}$ Over the course of their working careers, about $12.1 \%$ of cases $(2.1 \%$ of all workers $)$ recalled ever stopping work at a job or changing jobs because of back pain. An additional $9.6 \%$ of cases $(1.7 \%$ of all workers) recalled ever making a major change in their work activities because of back pain. As job changes could occur not only between jobs but also by leaving the work force, changes could attenuate relations such as those found here. Although in the epidemiological literature on causation such effects are most often regarded as healthy worker effects, ${ }^{33}$ those analyzing the links between experiences in the labour market and health conceptualise these relations as flowing in both directions. ${ }^{34}$

The association between high physical exertion and back problems is consistent with the extensive literature on the aetiology of low back pain. ${ }^{8}{ }^{9}$ However, those with musculoskeletal disorders may also rate physical factors differently, particularly psychophysical measures. Although some research on validation of a physical work load questionnaire on body posture and lifting or carrying included analysis of variance (ANOVA) to test for effects of musculoskeletal problems on psychological variables and did not find them, ${ }^{35}$ further research is warranted.

Inferences based on cross sectional health interview surveys are constrained by differential response rates to particular questions (as was found here), turnover of the working population, limitations in measurement, and temporal concerns in comparison with other study designs. Nevertheless, large scale population based surveys such as the NPHS offer some advantages. They cover representative samples of territorial populations, often with high response rates, and hence provide profiles of burden and risk factors relevant for policy purposes. Their findings are not limited to particular sectors or workplaces but cover a wide range of occupations. Sample sizes are usually sufficient to permit stratified analyses such as we have conducted here by sex. Thoughtful analyses of population surveys can facilitate generation of hypotheses, such as the two views of associations described here. Given the prevalent burden of musculoskeletal disorders found in working populations, such broad profiles and identification of research needs may become as relevant for occupational medicine practitioners and labour market policy makers, as for work and health researchers in the coming years.

\section{Appendix: \\ Chronic conditions}

BACK PROBLEMS

Do you have any of the following long term conditions (long term conditions refer to conditions that have lasted or are expected to last 6 months or more) that have been diagnosed by a health professional: (Read list. Mark all that apply)

(e) Back problems excluding arthritis?

(entire list of 23 conditions).

\section{Activity restrictions}

MUSCULOSKELETAL AND OTHER

The next few questions deal with any health limitations which affect your daily activities. In these questions, "long-term conditions" refer to conditions that have lasted or are expected to last 6 months or more.

Because of a long-term physical or mental condition or a health problem, are you limited in the kind or amount of activity you can do:

(a) at home?

Y Yes

No

$\overline{(b)}$ at school?

Yes

- No

Not applicable

(c) at work?

Y Yes

No

Not applicable

$\overline{(d)}$ in other activities such as transportation to or from work or leisure time activities?

$$
\text { Yes }
$$

No

RESTR-Q2 Do you have any long term disabilities or handicaps?

Y Yes

No

Activity restrictions: Any "yes" to RESTRQ1A to RESTR-Q2.

If any yes in RESTR-Q1 (a)-(d), ask RESTR-Q3.

RESTR-Q3 What is the main condition or health problem causing you to be limited in your activities?

(25 spaces)

If yes in RESTR-Q2 only, ask RESTR-Q4.

RESTR-Q4 What is the main condition or health problem causing you to have a long term disability or handicap?

(25 spaces)

Type of activity restrictions: derived variable DVRSTC94, a re-code of main health condition or health problem based on RESTR-Q3 and RESTR-Q4 from 4 digit or V ICD-9 codes to 12 system based categories. Musculoskeletal groups the following: arthritis, (6) limbs, (7) back and spine, (8) other; and diseases of the musculoskeletal system (9) limbs, (10) back, and (11) other. Other conditions group: (1) disease of nervous system and senses, (2) ischaemic heart disease, (3) other heart conditions, (4) other circulatory disorders, (5) diseases of repiratory and digestive systems, and (12) other. 
1 Makela M, Heliovaara M, Sievers K, et al. Musculoskeletal disorders as determinants of disability in Finns aged 30
years or more. F Clin Epidemiol 1993;46:549-59.

2 Reynolds DL, Chambers LW, Badley EM, et al. Physical disability among Canadians reporting musculoskeletal diseases. F Rheumatol 1992;19:1020-30.

3 Hurwitz EL, Morgenstern H. Correlates of back problems and back-related disability in the United States. F Clin Epidemiol 1997;50:669-81

4 Liira JP, Shannon HS, Chambers LW, et al. Long term back problems and physical work exposures in the 1990 Ontario health survey. Am 7 Public Health 1996;86:382-87.

5 Skovron ML, Szpalski M, Nordin M, et al. Sociocultural factors and back pain: a population-based study in Belgian adults. Spine 1994;19:129-37.

6 Saraste H, Hultman G. Life conditions of persons with and without low-back pain. Scand F Rehabil Med 1987;19:10913.

7 Houtman ILD, Bongers PM, Smulders P, et al. Psychosocial stressors at work and musculoskeletal problems. Scand $\mathscr{f}$ stressors at work and musculoskeletal

8 Riihimaki H. Back and limb disorders. In: McDonald C, ed. Epidemiology of work related diseases. London: 1995:207-38.

Frank JW, Kerr MS, Brooker A-S, et al. Disability resulting from occupational low back pain part I: what do we know about primary prevention? A review of the scientific evidence on prevention before disability begins. Spine 1996;21:2908-17.

10 Brooker A-S, Clarke J, Sinclair SJ, et al. Effective disability management and return to work practices. Toronto: Institute for Work and Health, 1998:1-14.

11 Statistics Canada HSD. National Population Health Survey, 1994-5, public use microdata files documentation. Ottawa, ON: Statistics Canada:1995.

12 Ibrahim SA, Shannon HS, Cole DC, et al. High strain and active jobs, job insecurity and self rated health in the 1994-5 Canadian National Population Health Survey data. Toronto: Institute for Work and Health, 1999. (Working paper 86.)

13 Karasek R. fob content questionnaire. Los Angeles, CA: Department of Industrial and Systems Engineering, Department of Industrial and System

14 Tambay JL, Catlin G. Sample design of the National Population Health Survey. Health Rep 1995;7:29-38.

15 Wilkins K, Beaudet MP. Work stress and health. Health Rep 1998;10:47-62.

16 Pineo PC. Revisions of the Pineo-Porter-McRoberts socioeconomic classification of occupations for the 1981 census. Hamilton, ON: Program for Quantitative Studies in Economics and Population, Faculty of Social Sciences, McMaster University, 1985:1-17. (Research Report No125.)

17 Dollard M.F, Winefield AH. A test of the demand-control/ support model of work stress in correctional officers. $f$ Occup Health Psychol 1998;3:243-64.

18 Papageorgiou AC, Macfarlane GJ, Thomas E, et al. Psychosocial factors in the workplace: do they predict new episodes of low back pain? Evidence from the South Manchester Back Pain Study. Spine 1997;22:1137-42.

19 Scott SC, Goldberg MS, Mayo NE, et al. The association between cigarette smoking and back pain in adults. Spine 1999;18:863-72.

20 Greenland S. Modeling and variable selection in epidemiologic analysis. Am F Public Health 1989;79:340-9.

21 Lee ES, Forthofer RN, Lorimer RJ. Analyzing complex survey data. Beverly Hills, CA: Sage, 1989.

22 Pfeffermann D. The use of sampling weights for survey data analysis. Stat Methods Med Res 1996;5:239-61.

23 Hosmer DW, Lemeshow S. Applied logistic regression. New York, NY: Wiley, 1989

24 SAS Institute. SAS/STAT user's guide. Version 6, 4th ed. Cary, NC: SAS Institute, 1989

25 Heliovaara M, Sievers K, Impivaara O, et al. Descriptive epidemiology and public health aspects of low back pain. Ann Med 1989;21:327-33.

26 Badley EM. The genesis of handicap: definition, models of disablement, and role of external factors. Disabil Rehabil 1995; 17:53-62.

27 Toomingas A, Theorell $\mathrm{T}$, Michelsen $\mathrm{H}$, et al. Associations between self rated psychosocial work conditions and musculoskeletal symptoms and signs. Scand $\mathcal{F}$ Work Environ Health 1997;23:130-9.

28 Bongers PM, de Winter CR, Kompier MAJ, et al. Psychosocial factors at work and musculoskeletal disease: a review of cial factors at work and musculoskeletal disease: a review of
the literature. Scand 7 Work Environ Health 1993;19:297312 .

29 Tarasuk V, Eakin JM. The problem of legitimacy in the experience of work-related back injury. Qualitative Health Research 1995;5:204-21.

30 Coyte PC, Asche CV, Crosford R, et al. The economic cost of musculoskeletal disorders in Canada. Arthritis Care and Research 1998;11:315-25.

31 Yelin E, Callahan LF. The economic cost and social and psychological impact of musculoskeletal conditions. Arthritis Rheum 1995;38:1351-62.

32 Guo H-R, Tanaka S, Cameron LL. Back pain among workers in the United States: national estimates and workers at high risk. Am f Ind Med 1995;28:591-602.

33 McMichael AJ. Standardized mortality ratios and the "healthy worker effect": scratching beneath the surface. $\mathcal{F}$ Occup Med 1976:18:165-8.

34 Lavis J. The links between labour-market experiences and health: towards a research framework. Hamilton, ON: McMaster University Centre for Health Economics and Policy Analysis; 1998.

35 Hollman S, Klimmer F, Schmidt K-H, et al. Validation of a questionnaire for assessing physical work load. Scand 7 Work Environ Health 1999;25:105-14.

36 Wiktorin C, Karlqvist L, Winkel J. Validity of self reported exposures to work postures and manual materials handling. Scand $\mathcal{F}$ Work Environ Health 1993;19:208-14.

\section{Rejected manuscripts}

Authors whose submitted articles are rejected will be advised of the decision and one copy of the article, together with any reviewer's comments, will be returned to them. The
Fournal will destroy remaining copies of the article but correspondence and reviewers' comments will be kept. 